\title{
A última voz humana viva: Uma leitura de Svetlana Aleksiévitch em um tempo de catástrofes
}

Pedro Telles da Silveira ${ }^{1}$

Resumo: Propõe-se aqui uma análise do livro Vozes de Tchernóbil, de Svetlana Aleksiévitch, contra o pano de fundo da bibliografia recente sobre temporalidade histórica e a respeito da atual mudança climática. Procura-se abordar o acidente nuclear da usina soviética como exemplo do que a autora afirma ser uma "história de catástrofes". Pensada com relação à ação humana, essa história de catástrofes se situa sobre a dissolução das fronteiras entre natureza e cultura e no interior de uma profunda alteração na escala do agir humano, que agora alcança escala planetária. Por isso, utiliza-se o desastre nuclear de Tchernóbil como forma de refletir a respeito do papel da história no chamado Antropoceno, período geológico caracterizado pela capacidade da agência humana de interferir nos ciclos naturais. Por fim, reflete-se acerca do tema do "fim do mundo" a partir da simultaneidade entre o desastre de Tchernóbil e o colapso da União Soviética.

Palavras-chave: Antropoceno - Temporalidade - Teoria da História Literatura Contemporânea

Abstract: What is proposed here is a reading of Svetlana Aleksiévitch's Voices of Chernobyl against the background of recent literatura about historical time and about the contemporary climate change. The paper analyses the nuclear disaster at the Soviet energy plan as an example of what Aleksiévitch calls a "history of catastrophes". If thought in relation with human agency, this history of catastrophes situates itself over the dissolution of the limits between nature and culture and inside a profound modification in the scale of human agency, which now extends over a planetary dimension. In

\footnotetext{
${ }^{1}$ Licenciado em História pela Universidade Federal do Rio Grande do Sul (2009) e mestre em História pela Universidade Federal de Ouro Preto (2012). Em 2013, retornou à UFRGS, onde concluiu o bacharelado e, no ano seguinte ingressou no doutorado em História, onde atualmente realize pesquisa sobre história digital e historiografia sob a orientação do Prof. Dr. Fernando Nicolazzi.
} 
this way, Chernobyl becomes a way to think about the role of history in the Anthropocene, a geological period caracterized by human capacity to influence and change natural cycles. It concludes with a reflection about the "end of the world" theme through the simultaneity between Chernobyl's nuclear disaster and the collapse of Soviet Union.

Keywords: Anthropocene - Temporality - Theory of History - Contemporary Literature

Em 26 de abril de 1986, na pequena cidade de Prípiat, situada na fronteira entre as repúblicas soviéticas da Ucrânia e de Belarús, ${ }^{2}$ o fogo brilhou como nunca brilhara antes. "Chegavam rumores de que era um fogo extraterrestre, que nem era fogo, mas uma luz. Uma reverberação. Uma aurora. Não de um azul qualquer, mas de um azulado celeste. E que a fumaça não era fumaça” (ALEKSIÉVITCH, 2016, p. 296). ${ }^{3}$ Era um fogo como nenhum outro, e todos que entravam em contato com ele carregavam em si um pouco desse fogo que não se extinguia, mesmo depois de mortos: "Ele estava morto, mas continuava quente, quente. Não se podia tocá-lo" (p. 362). E o incêndio continuou causando vítimas mesmo depois de apagado:

Muitos vão morrendo. Morrem de repente. Caminhando. Estão andando e caem mortos. Adormecem e não acordam mais. Está levando flores para uma enfermeira, e o coração para. Está

\footnotetext{
2 Também conhecida como Bielorrússia ou Rússia Branca, mantenho as soluções de transcrição adotadas por Sonia Branco ao longo de sua tradução. Isso se tornará patente ao utilizar a transcrição Tchernóbil ao invés das versões Chernobyl ou Chernobil mais conhecidas do público brasileiro.

${ }^{3}$ Como as referências ao livro de Svetlana Aleksiévitch são bastante numerosas, doravante cito apenas o número de página entre parênteses.
} 
no ponto de ônibus... Estão morrendo, e ninguém lhes perguntou de verdade sobre o que aconteceu ( $\mathrm{p}$. 38 ).

Todos que tomavam o caminho de volta, no entanto, ainda que não o reconhecessem, retornavam como se viessem de outro mundo, pois

Para aqueles que lá estiveram, Tchernóbil não terminava em Tchernóbil. Esses homens não regressaram de uma guerra, mais parece que voltaram de outro planeta... Eu compreendi que de maneira totalmente consciente aqueles homens convertiam os seus sofrimentos em novo conhecimento. Presenteavam-nos, dizendo: vocês haverão de fazer algo com isso, saberão como empregá-lo (p. 47)

“O que a experiência de Tchernóbil nos deu?” (p. 47), perguntase Svetlana Aleksiévitch em determinado momento de Vozes de Tchernóbil, e o que faremos deste estranho legado, cujo testamento ainda é um “signo que não sabemos ler”? (p. 41). Será possível essa apropriação, ou até mesmo pensá-la, se, nas palavras da autora,

Demos um salto para uma nova realidade, uma realidade que está acima do nosso saber e acima da nossa imaginação. Rompeu-se o fio do tempo... O passado de súbito surgiu impotente, não havia nada em que pudéssemos nos apoiar; e no arquivo onipotente (assim acreditávamos) da humanidade, não se encontrou a chave que abria a porta (p. 41). 
$\mathrm{O}$ acidente na usina nuclear de Tchernóbil demonstra que, ao longo do último século, a ruptura com a tradição foi menos o resultado das utopias que procuravam ordenar o mundo - ou das filosofias que buscavam justificá-las - do que causada pelo avassalador desenvolvimento da técnica; menos os efeitos de uma ruptura consciente com o passado do que a permanência de uma realidade cujo peso é grande demais para que seja movida; e menos a possibilidade de uma cesura voluntária do que o imperceptível manejo e controle cotidianos de um conjunto de ameaças que trazem a possibilidade, ainda que invisível, de conduzir ao desaparecimento do gênero humano na Terra. Quais os efeitos desse conjunto de possibilidades sobre o entendimento da história e a imaginação do futuro na passagem do século XX para o XXI? Qual será a história do novo século quando uma "história nova", uma "história de catástrofes" (p. 43), se abre após Tchernóbil?

Proponho aqui um exercício de leitura de Vozes de Tchernóbil em conjunto a algumas referências bibliográficas recentes (ou nem tanto) que abordam o tempo, a história, o futuro e a agência humana, de modo a entender como ambas se iluminam reciprocamente. Esse procedimento de leitura - idiossincrático, no mínimo - provê às páginas seguintes o caráter de uma resenha expandida sobre o coro de vozes orquestrado pela autora bielorrussa e fornece a oportunidade de uma leitura interdisciplinar de problemas recentes que têm ocupado a reflexão historiográfica. 
Um momento inicial do estudo é dedicado ao problema da técnica a partir da filosofia de Hannah Arendt e a superação dos sentidos físicos no interior do progresso científico moderno. $\mathrm{O}$ mal que se abateu sobre Tchernóbil ultrapassava as capacidades dos sentidos humanos de apreendê-lo e, por isso, indica uma ameaça incompreendida para aqueles que o viveram. O segundo momento introduz uma reflexão sobre o acidente nuclear à luz do conceito de Antropoceno e o desafio que traz ao entendimento tradicional da história e da atuação humanas. Por fim, explora-se a interconexão entre história humana e história natural através do entendimento cruzado do desastre nuclear de Tchernóbil e a queda da União Soviética como fim do mundo.

\section{A técnica e o emudecimento do mundo}

Em texto intitulado "A conquista do espaço e a estatura do homem", Hannah Arendt lembra que o avanço da ciência moderna teve com condição a "renúncia a uma visão de mundo antropocêntrica ou geocêntrica", assim como "uma eliminação radical de todos os princípios e elementos antropomórficos que surgem seja do mundo dado aos sentidos humanos, seja das categorias inerentes à mente humana" (ARENDT, 2007, pp. 326-327). Motivada pela exploração espacial, fenômeno que também instigara a última seção de $A$ condição humana, publicado originalmente em 1958, a filósofa alemã reconhecia no breve giro do satélite não-tripulado Sputnik pela órbita terrestre, realizado um ano antes, a passagem para a concretude do fenômeno que 
chamou de "alienação do mundo" que constituíra, desde o século XVI, o caminho em direção ao mundo e à ciência modernos:

É próprio da natureza da capacidade humana de observação só poder funcionar quando o homem se desvencilha de qualquer envolvimento e preocupação com o que está perto de si, e se retira a uma distância de tudo o que o rodeia. Quanto maior a distância entre o homem e o seu ambiente, o mundo ou a terra, mais ele pode observar e medir, e menos espaço mundano e terreno lhe restará. $\mathrm{O}$ fato de que o apequenamento definitivo da Terra foi consequência da invenção do aeroplano, isto é, de ter o homem deixado inteiramente a superfície da Terra, como que simboliza o fenômeno geral de que qualquer diminuição de distâncias terrestres só pode ser conquistado ao preço de colocar-se uma distância definitiva entre o homem e a Terra, de aliená-lo do seu ambiente imediato e terreno (ARENDT, 2004, p. 263).

O lançamento do satélite artificial em 1957 e a possibilidade de que o ser humano veja sua morada a partir de fora, realizada em 1961 pelo cosmonauta soviético Yuri Gagarin, mostram que a o avanço da ciência repousa - potencialmente - sobre a abstração das condições da vida humana na Terra. O conhecimento científico, reconhece a autora ao término do capítulo mencionado acima, se assenta no deslocamento do ser humano de sua posição de centralidade enquanto sujeito do conhecimento para uma posição lateral ou secundária; essa ciência, afirma ela, 
(...) seria geocêntrica no sentido de que a terra, e não o universo, é o centro e a morada dos homens mortais, e seria antropomórfica na acepção de que o homem incluiria sua própria mortalidade fatual entre as condições elementares indispensáveis para que seus esforços científicos sejam possíveis (ARENDT, 2007, p. 342),

De modo que ultrapassar o âmbito da existência dos indivíduos seria pré-condição para a obtenção do conhecimento. $\mathrm{O}$ avanço da ciência tornou insignificantes, portanto, todas as preocupações “antropocêntricas, isto é, verdadeira humanísticas” que guiavam a busca do saber (ARENDT, 2007, p. 327).

Essa alienação em relação ao mundo é resultado da contraposição entre o sensível e o imaginável. Segundo a autora, as "categorias e ideias da razão humana originam-se em última instância na experiência sensorial humana, e todos os termos que descrevem nossas capacidades mentais, bem como boa parte de nossa linguagem conceitual, derivam do mundo dos sentidos e são utilizados metaforicamente" (ARENDT, 2007, p. 333). Ora, o progresso da ciência se iniciou justamente com a imaginação de realidade que extrapolavam os dados perceptíveis aos seres humanos:

A moderna aventura científica começou com reflexões nunca pensadas antes (Copérnico imaginou que estivesse "postado no sol... observando os planetas") e com objetos nunca vistos antes (o telescópio de Galileu perfurou a distância entre a terra e o céu e liberou os segredos das estrelas à 
cognição humana (...)). De fato, Einstein tão-só generalizou essa ciência da época moderna ao introduzir um "observador suspenso livremente no espaço” (ARENDT, 2007, pp. 335-336).

Embora em todos esses casos ainda se possa pensar na maquinação do engenho humano capaz de elevar de suas condições de existência em busca de outros mundos conceituais, o corolário de todas essas criações de hipóteses é que, "Estritamente falando", os objetos da ciência

(...) não são fenômenos e aparências porquanto não os encontramos em parte alguma, nem em nosso mundo cotidiano nem no laboratório; sabemos de sua presença apenas porque afetam nossos instrumentos de mensuração de determinada maneira. (...) O ponto crucial é que (...) esses dados físicos emergem de um "mundo real', mais real por implicação, que aquele em que vivemos; o problema é que algo físico está presente, porém jamais aparece (ARENDT, 2007, p. 328).

Separados, o sensível e o cognoscível podem, até mesmo, excluir-se mutuamente - com resultados possivelmente desastrosos.

Nos relatos coletados por Svetlana Aleksiévitch, são comuns a resistência e a incompreensão acerca da radiação. "Da primeira vez em que nos disseram que tínhamos radiação, pensamos que se tratava de alguma doença, uma doença que logo levava a pessoa à morte. Mas nos diziam que não era isso, era algo que estava na terra, penetrando a terra, 
algo que não se podia ver" (p. 58). "O que se passou aqui é algo desconhecido. É outro tipo de horror. Não se vê, não se ouve, não tem cheiro nem cor" (p. 300). O mal é invisível e se manifesta apenas em pequenos sinais. Segundo os camponeses, as cristas das galinhas ficaram negras, o leite se esfarelava antes de azedar para produzir queijo, o gado passou três dias sem comer (p. 72).

Apartado do mundo dos sentidos, o conhecimento científico também não encontra mais expressão no âmbito da linguagem e do raciocínio humanos (ARENDT, 2004, p. 11). Entre ambos os polos, entretanto, situa-se o técnico, responsável por reestabelecer o contato entre "o mundo dos sentidos e das aparências e a visão de mundo da física" (ARENDT, 2007, p. 336). Cada avanço da físico-química ao longo do último século resultou numa miríade de instrumentos e aparelhos de aplicação cotidiana - seja em âmbito doméstico ou industrial - que servem como comprovações mais convincentes desses avanços do que "quaisquer observações ou experiências meramente científicas" (ARENDT, 2007, p. 336). Mas a tecnologia não é responsável por refletir ou procurar compreender, apenas em aplicar, esses saberes, e, com isso, "pode vir a suceder que nós, criaturas humanas que nos pusemos a agir como habitantes do universo, jamais cheguemos a compreender, isto é, a pensar e a falar sobre aquilo que, no entanto, somos capazes de fazer" (ARENDT, 2004, p. 11). Incapazes de refletir sobre seu próprio conhecimento ou de comunicá-lo, o resultado é a entrada num "modo de vida no qual o discurso não teria sentido" e 
no qual a política se encontraria subordinada à técnica (ARENDT, 2004, p. 11).

"Ninguém imaginava", afirma Svetlana Aleksiévitch, "que ambos os átomos, o de uso militar e o de uso pacífico, fossem gêmeos" (p. 43). Que os dois possam causar o mesmo dano, entretanto, indica que entre as tecnologias destinadas ao uso civil e aquelas direcionadas a fins bélicos, a diferença é apenas de aplicação, e não de natureza (NANCY, 2015, p. 18). Incompreensível no âmbito dos sentidos, o prelúdio à nossa reflexão iniciado pela abordagem do problema da ciência e da técnica em parcela da obra de Hannah Arendt aponta que o desastre nuclear de Tchernóbil também significa um desafio à compreensão do que sejam os limites da agência humana e da temporalidade na qual ela se inscreve. Meio século após a reflexão de Hannah Arendt, porém, o que está em jogo é a possibilidade de que a alienação do ser humano com relação ao mundo encontre um ponto extremo no qual a Terra deixa de ser sua moradia definitiva para se transformar em mera casa de passagem:

(...) naquele dia que aconteceu esse Tchernóbil maldito, eu sonhei com abelhas, com muitas, muitas abelhas. As abelhas saíam voando de uma colmeia atrás da outra, e voavam, voavam para bem longe. E quando você sonha com abelha, é sinal de incêndio. A terra vai incendiar. Deus deu o sinal de que o homem já não vive na terra como na sua casa; é um visitante. E nós estamos de visita aqui (p. 213). 


\section{Entre a pedra e o átomo}

Inserida numa história da técnica e seus impactos, a catástrofe nuclear de Tchernóbil pode ser comparada a outro incêndio que chamou a atenção da reflexão historiográfica recentemente, aquele que foi extinto na província chinesa de Xinjiang no ano de 2004 após ter queimado - ininterruptamente - por 130 anos (LORENZ, 2014, p. 44). Para o historiador holandês Chris Lorenz, "um incêndio extremo como esse simplesmente expande nossa ideia normal do que é um incêndio. (...) Tal incêndio se situa literalmente para além da nossa imaginação" (LORENZ, 2014, P. 45), pois não é próprio dos incêndios como nós os conceitualizamos que eles atravessem décadas e, até mesmo, séculos. Não é preciso muito, entretanto, para perceber que a chama de Tchernóbil é mais espectral e duradoura do que o exemplo destacado por Lorenz.

Segundo Svetlana Aleksiévitch, o acidente de Tchernóbil "se assemelhava a um monstro" (p. 41). Isso não é dito, no entanto, para destacar sua onipresença midiática, como já foi ressaltado em outros trabalhos teóricos contemporâneos, embora o acontecimento tenha se impregnado rapidamente na consciência europeia. Tchernóbil assemelha-se a um monstro porque redimensiona a escala humana de atuação em ambas as pontas do espectro: o micro e o macroscópico. $\mathrm{O}$ incidente atua simultaneamente ao nível genético - infinitesimal do ponto de vista humano - e sobre vastas extensões geográficas: 
Até hoje usamos os termos antigos: "longe-perto", "próprio-alheio"... Mas o que significa longe e perto depois de Tchernóbil, quando já no quarto dia as suas nuvens sobrevoavam a África e a China? A Terra parece tão pequena, não é mais aquela Terra do tempo de Colombo. Infinita. Hoje possuímos outra sensação de espaço. Vivemos num espaço arruinado. E ainda... (p. 49).

E o mesmo ocorre com as categorias ligadas à compreensão do tempo:

Nos últimos anos, o homem passou a viver mais, mas o seu tempo de vida continua a ser minúsculo e insignificante se comparado à vida dos radionuclídeos instalados na nossa terra (p. 49).

Nesse sentido, “Tchernóbil é antes de tudo uma catástrofe do tempo. Os radionuclídeos espalhados sobre a nossa terra viverão cinquenta, cem, 200 mil anos. Ou mais. Do ponto de vista da vida humana, são eternos" (p. 39). A longa duração dos efeitos - indesejados - de Tchernóbil é tanto mais frustrante quanto a consciência de que os desejos de preservação e conservação alimentados pela cultura contemporânea são irrealizáveis (ASSMANN, 2011, pp. 373-374). Tchernóbil força considerar a atuação humana ao nível do corpo e da espécie, mas não - e isso é significativo - enquanto sujeito político.

Para Chris Lorenz, o incêndio de Xinjiang serve de metáfora para um passado que não "esfria" conforme se distancia no tempo (LORENZ, 2014, p. 46). O passado que não se distancia é resultado de 
uma transformação na experiência do tempo, o qual deixou de ser linear, irreversível e progressivo para se tornar seu oposto: não-linear, reversível e passível de retrogressão (LORENZ, 2014, p. 46). Sobre Tchernóbil, é constante essa sensação. Segundo uma das vozes registradas, "voltamos cem anos no tempo" (p. 76), e a própria autora se pergunta: "eu sou testemunha de quê, do passado ou do futuro?" (p. 49). Segundo Lorenz, o tempo não-linear permite pensar que "o passado pode viver no presente assim como o futuro pode estar presente no presente" (LORENZ, 2014, p. 46) - e Tchernóbil, sintomaticamente, possui a tendência a estranhas sobreposições temporais, uma experiência radical daquilo que Reinhart Koselleck chamou de "simultaneidade do não-simultâneo" (KOSELLECK, 2006, p. 96).

Não deixa de ser com irônica melancolia que uma das testemunhas ouvidas pela autora relata que

No primeiro dia, vimos a central nuclear de longe. No segundo, já recolhíamos os resíduos à sua volta. Carregávamos os detritos em baldes. Usávamos pás comuns, varríamos o chão com vassouras como as que os zeladores usam para varrer os pátios. E raspadeiras. Está claro que as pás eram apropriadas para areia e cascalho. E não para resíduos como aqueles, onde havia de tudo: pedaços de película, de ferro, de madeira e de concreto. Era como quem luta contra o átomo com uma pá. Século XX... (p. 118; grifo meu).

O mesmo com relação aos operários da usina: 
Dentre os trabalhadores da central de Tchernóbil, muitos eram camponeses. De dia, estavam nos reatores, e à noite, cuidando das suas hortas, ou na casa dos pais, na aldeia vizinha, plantando batatas com a pá ou espalhando esterco com a forquilha. Extraindo a colheita, também com as mãos. A sua consciência oscilava entre dois tempos, entre duas eras: a da pedra e a atômica. E o homem, como um pêndulo, movia-se de um extremo a outro (pp. 265266; grifo meu).

Entre a pedra e o átomo, a autora confirma a incongruência temporal experimentada pelos que trabalharam na remoção dos resíduos nucleares de Tchernóbil e no estabelecimento da zona de exclusão em torno à usina:

Lembram-se das aldeias desertas por que passaram, encontrando por vezes idosos solitários que haviam se recusado a partir com os outros, ou que mais tarde haviam regressado do exílio: homens que viviam à luz da lamparina, que ceifavam com a gadanha e a foice, que cortavam lenha com o machado, que dirigiam as preces aos animais e aos espíritos. Tudo como há duzentos anos, enquanto naves espaciais sulcavam o се́u (p. 46; grifo теu).

Para além destes exemplos, no entanto, creio que a crise do tempo exposta por Chris Lorenz e exemplificada por Tchernóbil manifesta um problema profundo, qual seja, a interpenetração entre o tempo histórico e o tempo da natureza. 
Segundo o historiador indiano Dipesh Chakrabarty, em pioneiro texto intitulado "O clima da história: quatro teses", a atual catástrofe ambiental acarreta o "fim da velha distinção humanista entre história natural e história humana" (CHAKRABARTY, 2013, p.5). Essa distinção atravessou as concepções de história desde a Antiguidade até o mundo moderno. Como já destacou Hannah Arendt,

Quando Sófocles (no famoso coro da Antígona) diz que não há nada mais inspirador de temor que o homem, ele prossegue, para exemplificá-lo, evocado atividades humanas propositadas que violentam a natureza por conturbarem o que, na ausência dos mortais, seria a eterna quietude do ser-para-sempre que descansa ou oscila dentro de si mesmo (ARENDT, 2007, p. 77).

O tempo histórico emerge sob a forma da mortalidade e da finitude sobre a constância e a perenidade do mundo natural ou, na bela formulação da autora, é um "mover-se ao longo de uma linha retilínea em um universo onde tudo, se é que se move, se move em uma ordem cíclica" (ARENDT, 2007, p. 77). Já para Reinhart Koselleck, no processo de consolidação do conceito moderno de história, esta "foi reestruturada em forma de uma grandeza não natural" e, como consequência, "Natureza e história puderam desde então separar-se conceitualmente" (KOSELLECK, 2006, p. 54) Apesar de os indivíduos interagirem, reagirem ou serem por ela condicionados, o tempo da natureza e o tempo dos seres humanos permaneciam essencialmente 
opostos. "O ambiente", destaca Chakrabarty, "se modificava, mas o fazia de forma tão lenta que relacionar a história humana com seu entorno assumia uma característica quase atemporal, o que excluía essa relação do domínio da historiografia" (CHAKRABARTY, 2013, p.8). Em comparação, o momento atual revela que

(...) o clima, e consequentemente todo o meio ambiente, pode às vezes atingir um ponto máximo a partir do qual sua condição de pano de fundo lento e aparentemente atemporal se transforma com uma velocidade tamanha que só pode ser desastrosa aos seres humanos (CHAKRABARTY, 2013, p. 8).

Essa aceleração do tempo da natureza decorre da ampliação vertiginosa da escala da atuação humana. Segundo Chakrabarty, o ser humano se transformou em muito mais do que "o simples agente biológico que sempre foi. Os seres humanos agora exercem uma força geológica" (CHAKRABARTY, 2013, p. 8). Esse aspecto caracteriza o chamado Antropoceno. Proposto pelos geólogos Paul Crutzen e Eugene Stoermer, a categoria designaria uma "nova época geológica que se seguiu ao Holoceno, a qual teria se iniciado com a Revolução Industrial e se intensificado após a Segunda Grande Guerra" (DANOWSKI; VIVEIROS DE CASTRO, 2014, p. 19). O que distingue o Antropoceno é o fato de que "alcançamos números e inventamos tecnologias" que possuem "uma escala suficientemente grande para causar impacto no próprio planeta" e por uma escala temporal que excede as dimensões naturais da longevidade dos indivíduos ou sociais das instituições 
humanas (CHAKRABARTY, 2013, p. 9) - como os radionuclídeos de Tchernóbil, presentes por duzentos mil anos na Terra.

Ainda segundo Chakrabarty, o aquecimento global atualmente em ocorrência impõe a necessidade de pensar simultaneamente em três escalas: a história da Terra enquanto sistema geológico e biológico; a história da vida na Terra e a evolução das espécies, incluindo o gênero humano; e a história mais recente do desenvolvimento técnicoindustrial e econômico do sistema capitalista (CHAKRABARTY, 2013, p. 1). Uma vez que a agência humana se expandiu para além da esfera propriamente humana, a história atravessa e articula essas três escalas, o que aponta a necessidade de repensar a atuação humana ao longo e na história.

Como já destacou Reinhart Koselleck, foi apenas no final do século XVII que se tornou possível "imaginar que se pudesse fazer a história" (KOSELLECK, 2006, p. 234). Teria sido apenas quando a história se transformou num conceito singular e com motivação própria - ou seja, a história em si, ao invés de a história de algo-,que ela "pareceu estar disponível aos homens, ou pode ser pensada como factível" (KOSELLECK, 2006, p. 236). No término desse processo, a possibilidade do fazer histórico humano se consolidou sobre o pano de fundo de uma "renúncia a uma instância extra-histórica", pois

Para experimentar ou reconhecer a história em si não era mais necessário recorrer a Deus ou à natureza. Em outras palavras: a história, experimentada como 
nova, tinha de antemão o sentido de história universal. Deixou de ser uma história que se realiza neste mundo por meio da humanidade e com a humanidade. Nas palavras de Schelling, em 1798: o homem tem história "porque não leva sua história consigo - ele mesmo a produz" (KOSELLECK, 2006, p. 237).

Os indivíduos são agentes de sua própria história, e não veículo de um motor transcendental - a providência divina sendo o mais conhecido deles. É essa disponibilidade da história que encontra-se questionada ao mesmo tempo que a agência humana se estende em direção à natureza.

Segundo Isabelle Stengers, nos situamos atualmente não apenas diante 'de uma natureza 'que deve ser protegida' contra os danos causados pelos homens, mas também de uma natureza capaz de incomodar, de uma vez por todas, nossos saberes e nossas vidas" (STENGERS, 2015, p. 1). Essa "súbita colisão dos Humanos com a Terra", como o resumem Déborah Danowski e Eduardo Viveiros de Castro, significa o "retorno definitivo de uma forma de transcendência que acreditávamos haver transcendido, e que agora reaparece mais forte do que nunca":

A transformação dos humanos em força geológica, ou seja, em um fenômeno "objetivo", em um objeto "natural", em um "contexto" ou "ambiente condicionante", se paga assim com a intrusão de Gaia no mundo humano, dando ao Sistema Terra a forma ameaçadora de um sujeito histórico, um 
agente político, uma pessoa moral (DANOWSKI; VIVEIROS DE CASTRO, 2014, p. 26).

Essa nova transcendência é o reconhecimento de que o mundo histórico se encontra invadido por outros "sujeitos" - agenciamentos que se sobrepõem, quando não são opostos, ao âmbito humano de atuação, de modo que a história não é mais apenas o teatro da sociedade ou da cultura, mas o local de incidência da própria dissolução entre natureza e cultura.

Pode-se pensar, com Hannah Arendt, valendo-se de uma parábola de Franz Kafka, que o progresso do conhecimento humano se deu com a condição de que ele fosse utilizado contra si mesmo, limitando o estatuto do ser humano (ARENDT, 2007, p. 341). Nesse sentido, a ampliação da escala da agência humana encontra como limite a transcendência com relação ao próprio aspecto humano que a condicionava - como dito acima, o ser humano enquanto corpo ou espécie, mas não mais como sujeito político. Essa situação é paralela daquela pensada por Jean-Luc Nancy à sombra de outro acidente nuclear, o de Fukushima, em 2011. Segundo o filósofo francês, "catástrofes naturais não são mais distinguíveis de suas implicações ou repercussões tecnológicas, econômicas e políticas" (NANCY, 2015, p. 4). "Daqui para frente", afirma,

(...) existirá uma interconexão, um entrelaçamento, até mesmo uma simbiose de tecnologias, trocas, movimentos, que fazem uma enchente - por 
exemplo -, onde quer que ela ocorra, necessariamente envolver relações com uma certa quantidade de aspectos técnicos, sociais, econômicos e políticos intrincados entre si que evitam que a consideremos simplesmente como um acidente ou uma infelicidade cujas consequências podem ser mais ou menos facilmente circunscritas (NANCY, 2015, pp. 3-4).

Embora nomes como Auschwitz e Hiroshima já tenham nos aproximado do fim da humanidade enquanto tal, outros nomes, como Tchernóbil e Fukushima, nomes ainda por escrever, como o colapso das barragens da mineradora Samarco, em Mariana, Minas Gerais, ou nomes que ainda não conseguimos de todo pronunciar, como o aquecimento global, se diferenciam daqueles dois eventos-chave do século XX porque eles foram resultado do "planejamento consciente dos poderes constituídos", enquanto os últimos exemplos "são frutos de ações humanas não-intencionais e mostram, somente através de análise científica, os efeitos de nossas ações enquanto espécie” (CHAKRABARTY, 2013, p. 22). Esses acontecimentos são nãointencionais mas, ao mesmo tempo, possuem a agência humana - os chamados "fatores antrópicos" - como uma de suas condições de possibilidade; numa escala geológica de atuação, as consequências dos atos humanos possuem - e possuirão - sempre um "excesso", uma transcendência, com relação ao tempo e à geografia humanos. Num futuro que já vivenciamos, portanto, os “acidentes” serão uma parcela cada vez maior dos acontecimentos históricos - eles são a própria 
materialização do entrecruzamento, frequentemente catastrófico, entre o tempo da natureza e o tempo da cultura. Para Jean-Luc Nancy,

Não existem mais catástrofes naturais. Existe apenas uma mesma catástrofe civilizacional que se expande continuamente. Isso pode ser demonstrado cada vez que acontece uma das supostas catástrofes naturais terremotos, enchentes ou erupções vulcânicas - para não mencionar as perturbações na natureza causadas por nossas tecnologias (NANCY, 2015, P. 34).

Não se deve estranhar, portanto, quando uma das testemunhas ouvidas por Svetlana Aleksiévitch afirma que "Tchernóbil fica muito além de Kolimá e de Auschwitz. Do Holocausto. Estou me expressando com clareza?", porque "O homem armado de machado e arco ou com lança-granadas e câmara de gás não pode matar todo mundo. Mas o homem com o átomo...” (p. 280).

Essa incomensurabilidade dos atos humanos lança uma estranha sombra sobre a ideia de que os indivíduos fazem a história. Embora o argumento de Koselleck possua um ponto de inflexão - para ele, a história se caracteriza "pelo fato de que, com o decorrer do tempo, as previsões e os planos dos homens são sempre diferentes de sua realização" (KOSELLECK, 2006, p. 242) e, por isso, a possibilidade da história encontra-se justamente nesse intervalo entre o planejado e o realizado -, o atual contexto leva ao limite a possibilidade de os resultados diferirem do planejado: 
$\mathrm{Na}$ realidade, estávamos indefesos. Essa era a principal sensação que tínhamos naqueles dias. Que em algum lugar bem longe estava Gorbatchóv. E mais algumas pessoas. Dois ou três homens decidiam o nosso destino. Da mesma forma que outro punhado de homens podia nos matar. Não maníacos ou criminosos com planos terroristas na cabeça, mas os corriqueiros operadores de plantão da central atômica. Bons rapazes, por sinal (p. 280; grifo meu).

Por esse motivo, pode-se concordar com Svetlana Aleksiévitch quando ela afirma que, com Tchernóbil, chegou-se ao "entendimento de que nos encontrávamos diante de uma história nova: teve início a história das catástrofes..." (p. 43).

O estabelecimento de uma agência em escala planetária dos humanos enquanto espécie, impõe como consequência, aparentemente contraditória, que essa atuação é ilimitada, pois só responderia aos imperativos da própria ação humana - "alienada" do mundo no sentido proposto por Hannah Arendt, e, por isso, o ser humano só encontrará a si numa natureza fabricada por ele mesmo (ARENDT, 2004, p. 342; NANCY, 2015, p. 4) - ao mesmo tempo que encontrou seu limite transcendental: o desencadeamento de efeitos numa escala muito maior do que é comum ou possível imaginar enquanto indivíduos históricos ou agentes políticos (CHAKRABARTY, 2013, p. 3), e que são indiferentes ou desproporcionais com relação aos atos humanos que as ocasionaram. Embora seja próprio da situação que vivemos a 
necessidade de pensar simultaneamente em escalas incongruentes que não são necessariamente concêntricas (CHAKRABARTY, 2013, p. 3), uma vez que o próprio centro foi removido, o problema, novamente, parece ser mais profundo:

O Antropoceno (...) é uma época, no sentido geológico do termo, mas ele aponta para o fim da "epocalidade" enquanto tal, no que concerne à espécie. Embora tenha começado conosco, muito provavelmente terminará sem nós: o Antropoceno só deverá dar lugar a uma outra época geológica muito depois de termos desaparecido da face da Terra (DANOWSKI; VIVEIROS DE CASTRO, 2014, p. 16).

Trata-se, portanto, não apenas do fim do conceito moderno de história, mas do fim da história. É hora de falar do futuro.

\section{O fim do mundo soviético como fim do mundo}

"A disciplina da história", recorda Dipesh Chakrabarty, "existe tendo como pressuposto que nosso passado, presente e futuro estão ligados por uma certa continuidade da experiência humana", de modo que "Normalmente enxergamos o futuro com o auxílio da mesma faculdade que nos permite representar o passado" (CHAKRABARTY, 2014, p. 2). O efeito concatenado das três temporalidade - passado, presente e futuro - provê de sentido o devir humano; por esse motivo, momentos de ruptura qualificam o passado como incapaz de fornecer instrumentos conceituais que permitam a compreensão do presente. A 
atual crise ecológica, no entanto, "pode precipitar um senso do presente que separa o futuro do passado ao colocar tal futuro além do alcance da sensibilidade histórica" (CHAKRABARTY, 2014, p. 2). Não se trata de dizer que o fio que une os três tempos se rompeu; pelo contrário, a crise que vivemos é consequência direta - um "karma geofísico", no dizer de Danowski e Viveiros de Castro (2015, p. 16) - de práticas e hábitos historicamente datados, mas sim de apontar a desproporção entre esses atos em suas dimensões individuais, sociais ou políticas e suas consequências biológicas e geológicas. Essa incongruência brutal entre passado e futuro transforma o presente no lugar instável no qual se torna até mesmo difícil imaginar ou representar a catástrofe que vivemos, a não ser sob formas negativas.

Conforme se reconhece a gravidade da "presente crise ambiental e civilizacional", retoma-se com crescente insistência o tema - "antiquíssimo" - do fim do mundo (DANOWSKI; VIVEIROS DE CASTRO, 2014, p. 11), que deixa de ser marginal para se transformar em fenômeno de interesse coletivo (HACHE, 2014, p. 8). Aparentemente simples, a expressão "suscita necessariamente o problema correlato do fim do pensamento, isto é, o fim da relação (...) entre pensamento e mundo" (DANOWSKI; VIVEIROS DE CASTRO, 2014, p. 32). Nesse sentido, o "fim do mundo" só tem sentido caso se determine "simultaneamente para quem este mundo que termina é mundo, quem é o mundano ou o 'mundanizado' que define o fim" 
(DANOWSKI; VIVEIROS DE CASTRO, 2014, p. 33). Surgem, então, os pólos que enquadram o espectro do "fim do mundo":

De maneira muito simples, podemos partir da oposição entre um "mundo sem nós", isto é, o mundo depois do término da existência da espécie humana, e um "nós sem mundo", uma humanidade desmundanizada ou desambientada, a subsistência de alguma forma de humanidade ou subjetividade após o fim do mundo (DANOWSKI; VIVEIROS DE CASTRO, p. 35).

A segunda possibilidade permite pensar na sobrevivência dos agentes - humanos ou não - após o fim do mundo, o que remete ao fato de que o mundo só termina para aqueles para os quais o mundo era, de fato, mundo. Pode-se, então, utilizar o conceito de "fim do mundo" como categoria operacional para perscrutar os diversos "fins" do mundo, alguns dos quais já aconteceram. É o que proponho para Tchernóbil.

Pode-se dizer que os sobreviventes de Tchernóbil encontramse "em suspenso entre duas histórias", como destaca Isabelle Stengers (2015, p. 7). Uma história é ritmada "pelas notícias do front da grande competição mundial, e seu crescimento segue a flecha do tempo"; a outra, por sua vez, "pode ser pensada como nítida quanto ao que está acontecendo, mas obscura no que exige, na resposta àquilo que está acontecendo" (STENGERS, 2015, p. 7). Com essa metafora, a filósofa belga aponta a "enorme distância entre conhecimento científico e 
impotência política, isto é, entre nossa capacidade (científica) de imaginar o fim do mundo e nossa incapacidade (política) de imaginar o fim do capitalismo" (DANOWSKI; VIVEIROS DE CASTRO, 2014, p. 31), o que também é apontado por Dipesh Chakrabarty quando relembra que "especialistas em política pensam em termos de anos, décadas, séculos, no máximo, enquanto políticos nas democracias pensam em termos de ciclos eleitorais" (CHAKRABARTY, 2014, p. 3), dois referentes temporais inadequados para compreender - ou pensar em reverter - as imprevisíveis transformações climáticas que engendramos.

Embora se possa objetar que Tchernóbil tenha ocorrido em território socialista e não capitalista, o livro de Svetlana Aleksiévitch oferece inúmeros exemplos de conflito ou incongruência entre as duas histórias. Pode-se percebê-los no relato de uma testemunha, ex-diretor do Instituto de Energia Nuclear da Academia de Ciências de Belarús, e suas fracassadas tentativas de encetar uma ação organizada de conscientização da população por parte das autoridade soviéticas (pp. 322; 326), ou na censura aplicada sobre os registros imagéticos do acidente e suas consequências locais (p. 219).

O descompasso entre as duas histórias, no entanto, adquire maior significação quando se observam os confrontos entre os modos disponíveis aos soviéticos para entender o que está acontecendo e as exigências que Tchernóbil impõe para sua compreensão:

De início houve perplexidade geral. A sensação de que se tratava de manobras militares. De um jogo. 
Mas era uma guerra de verdade. Uma guerra atômica... Algo desconhecido para nós: o que temer e o que não temer, o que evitar e não evitar? Ninguém sabia. E não havia ninguém que pudesse responder (pp. 111-112).

Não eram apenas os civis que estavam despreparados para a ocasião, mas também os comandantes militares:

A minha mãe justificava: "Se tivesse começado uma guerra, saberíamos o que fazer. Para a guerra, dispúnhamos de instrução. Mas isso?’.

Quem encabeçava a nossa defesa civil? Generais e coronéis para quem a guerra começa da seguinte forma: estações de rádio transmitem as declarações do governo, alarme aéreo, projéteis explosivos, bombas incendiárias. Eles não se davam conta de que estávamos em outra época (p. 330).

Numa sociedade caracterizada pelo militarismo e na qual a memória da guerra era um dos atributos da nacionalidade - e na qual a experiência bélica continuava "sendo o termo de medida" (p. 70) -, a experiência de Tchernóbil é como a deposição de uma camada de solo estranha a essa paisagem saturada de história, como diz a autora ao trazer sua própria voz como testemunho:

"Teria sido mais fácil nos acostumar à situação de uma guerra atômica como a de Hiroshima, pois sempre nos preparamos para ela. Mas a catástrofe aconteceu num centro atômico não militar (...) Passamos a vida lutando e nos preparando para a 
guerra, tão bem a conhecíamos e, de súbito, isso! A imagem do inimigo se transformou. Surgiu diante de nós um outro inimigo... Inimigos... que tocavam a relva ceifada, o peixe pescado, a caça aprisionada. As maçãs... O mundo à nossa volta, antes maleável e amistoso, agora nos infundia pavor. As pessoas mais velhas, ao serem evacuadas e ainda sem perceber que isso seria para sempre, olhavam para o céu e diziam: 'O sol está brilhando, não se vê fumaça nem gás. Não se escutam tiros. Como isso pode ser uma guerra? No entanto, devemos nos tornar refugiados", (pp. 42; 44-45).

Contra esse novo inimigo, o conhecimento oferecido pela literatura não era mais suficiente, como o relato de uma professora acerca de seus alunos:

Deixaram de amar os clássicos, eu recito Púchkin de cor para eles e vejo os seus olhares frios, ausentes... Há um vazio... O mundo em torno deles é outro (...). Às vezes me vem o pensamento sacrílego de que a nossa cultura não é mais que um baú de velhos manuscritos (pp. 164; 168; grifo meu).

Outra testemunha reafirma novamente o contraste entre o passado militar e o desafio presente: “(...) uma guerra nuclear, o rádio da explosão. Isso eu até podia imaginar. Mas o que aconteceu conosco... Para isso me faltava... me faltavam conhecimentos, e faltavam em todos os livros que eu havia lido na minha vida" (pp. 172-173). A conclusão é que “(...) precisamos mais que nunca de outros livros, porque a vida à nossa volta é outra. E nós somos estranhos nela" (p. 283). "Estávamos 
acostumados a acreditar", afirma uma testemunha. "Eu sou da geração pós-guerra, que cresceu nessa fé. De onde veio essa fé? Nós vencemos uma guerra tão terrível! O mundo todo nos reverenciou" (p. 255). Tudo isso pouco importa agora:

Falam da guerra. Da geração da guerra. Comparam... A geração da guerra? Mas ela é feliz! Tiveram a Vitória. Eles venceram! Isso lhes deu uma grande energia vital, ou, como se diz agora, uma poderosa carga de vivência. Eles não temiam nada. Queriam viver, estudar, ter filhos. E nós? Nós temos medo de tudo. Tememos pelos nossos filhos, pelos netos que ainda não temos. Ainda não existem e já tememos por eles (p. 291).

Por esses motivos,

O acontecimento ainda está à margem da cultura. É um trauma da cultura. E a nossa única resposta é o silêncio. Fechamos os olhos como crianças pequenas e acreditamos que assim nos escondemos, que o horror não nos alcançará (p. 130).

Segundo a autora, no acidente nuclear "Confluíram duas catástrofes: a social - aos nossos olhos arruinou-se a União Soviética, submergiu sob as águas o gigantesco continente socialista - e a cósmica - Tchernóbil":

A primeira nos é mais próxima, mais compreensível. As pessoas estão preocupadas com o dia a dia, com o cotidiano: o que comprar, aonde ir? No que 
acreditar? Levantar-se novamente sob que bandeira? Ou será preciso aprender a viver para si, viver a sua vida? Já a última nos é desconhecida, não sabemos o que fazer, porque ninguém nunca viveu assim. Isso é algo que experimentamos todos e cada um. Gostaríamos de esquecer Tchernóbil, porque diante dele a nossa consciência capitula. É uma catástrofe da consciência. $\mathrm{O}$ mundo das nossas representações e valores explodiu. Se tivéssemos vencido Tchernóbil ou compreendido o fenômeno até o fim, pensaríamos e escreveríamos mais a respeito. $E$ assim, vivemos em um mundo enquanto nossa consciência vive em outro (p. 49; grifo meu).

Tchernóbil oferece o triste espetáculo de um “apocalipse sem revelação" (NANCY, 2015, p. 20), pois "Ingressamos num mundo opaco, onde o mal não dá explicações, não se revela e não conhece leis" (p. 45). Embora seja despropositado culpar Tchernóbil pela queda da União Soviética, não é possível, no entanto, separar ambos os acontecimentos, pois na medida em que os humanos interferem ativamente no funcionamento da Terra, se realiza o "desmoronamento da distinção fundamental da episteme moderna - a distinção entre as ordens cosmológica e antropológicas, separadas desde 'sempre' (quer dizer, desde pelo menos o século XVII) por uma dupla descontinuidade, de essência e de escala" (DANOWSKI; VIVEIROS DE CASTRO, 2014, p. 26). Com isso, o sonho de remodelar a natureza e todo o voluntarismo que o caracterizava esbarra no limite imposto pela própria Terra e sua agência imprevisível aos olhos humanos; apesar dos 
inúmeros exemplos de heroísmo, que conseguiram evitar uma catástrofe ainda maior, Tchernóbil representa o fim de uma realidade política abstraída - "alienada", no dizer de Hannah Arendt - das condições "naturais" na qual se insere. Por causa dessa dupla catástrofe, “Agora já não mais podemos crer, como os heróis de Tchékhov, que dentro de cem anos o ser humano será maravilhoso. Que a vida será maravilhosa! Esse futuro nós já perdemos" (p. 50).

Não me parece à toa que alguns testemunhos apresentem uma súbita transformação da vida soviética após Tchernóbil. "Depois de Tchernóbil", afirma uma testemunha, "Nós temos aprendido a dizer 'eu'” (p. 334):

Tchernóbil fez surgir o sentimento novo e incomum de que cada um de nós tem a sua própria vida; até então isso parecia desnecessário. $\mathrm{E}$ as pessoas passaram a se preocupar com o que comiam, como alimentavam os filhos, o que seria ou não perigoso para a saúde, se mudavam ou não para outro lugar. Cada um tinha de tomar as suas próprias decisões. Antes, como se vivia? Com toda a aldeia, com toda a comunidade. Com o coletivo da fábrica ou do colcoz. Nós éramos soviéticos (pp. 258-259).

Trata-se da frustração com o fracasso das utopias, das quais o comunismo era a derradeira; da ruptura com um passado em comum que conduzia inequivocamente ao futuro, que continha em si o horizonte da felicidade; da impossibilidade de uma leitura dualista da realidade da qual a Guerra Fria foi o maior exemplo - em Tchernóbil, 
procurava-se os agentes infiltrados ocidentais, responsáveis pelo incidente (p. 45). Diante de Tchernóbil,

As pessoas passaram a se preocupar com a vida cotidiana, o que comprar e como sobreviver. Em que acreditar e sob qual bandeira novamente se erguer. Ou seria necessário aprender a viver sem uma grande ideia? Essa última solução não era nada familiar, ninguém nunca tinha vivido assim. $\mathrm{O}$ "homem vermelho" se viu confrontado a centenas de perguntas, e em face delas se encontrou totalmente só (p. 381).

E, nesse estado de solidão, o cidadão soviético "não pôde entrar naquele reino de liberdade que sonhou na sua cozinha" (p. 382).

A queda da União Soviética motivou toda sorte de especulações a respeito do "fim da história", das quais a de Francis Fukuyama é a mais conhecida. Ao reduzir a escala de análise para o indivíduo - onde "tudo acontece", diz a autora -, parece-me possível considerar que o término da história soviética coincide com o fim do "mundo", tanto cultural quanto social, no qual ele existia (p. 372). Na solidão do "homem vermelho" e no caráter incognoscível de Tchernóbil em termos de uma história de guerras, mas não de uma história de catástrofes, é possível reconhecer que "os Humanos (...) já perderam a guerra; [pois] seu mundo já acabou" (DANOWSKI; VIVEIROS DE CASTRO, 2014, p. 154). No caso russo, o mundo soviético acabou porque o mundo soviético não existe mais. 
Pode-se imaginar um mundo sem história - seja nas versões de um mundo antes da Queda ou de um futuro no qual os humanos não mais existem -, mas é possível pensar numa história sem mundo? Não seria possível, então, ao menos pensar que seres humanos, mundo e história não são mais termos necessários ou que se remetem entre si? E se, na ausência de um mundo, for possível renunciar à história?

Houve um tempo... houve um em que eu invejava os heróis. Aqueles que tinham participado dos grandes acontecimentos, que viveram épocas de ruptura, momentos de reviravolta da história. Falávamos e cantávamos sobre eles. Havia canções muito bonitas. (...) Eu sonhava! Lamentava não estar lá em 1917 ou em 1941. Hoje penso de outra forma: eu não quero viver a história, no tempo histórico. A minha pequena vida ficaria imediatamente sem defesa. Os grandes acontecimentos a esmagariam sem sequer notá-la (p. 270; grifo meu).

Ao observar os camponeses e sua capacidade de adivinhar, antes dos informes oficiais, apenas através da reação dos animais, a catástrofe que vem, a autora se pergunta: "Quem de nós é o primeiro, quem está mais sólida e eternamente ligado à terra, nós ou eles? Devíamos aprender com eles como sobreviver. E como viver" (p. 48).

Em Tchernóbil, "O tempo mordeu o próprio rabo, o início e o fim se tocaram" (p. 47) e o futuro se encontra no passado. Talvez renunciar à história seja uma forma que os humanos encontrem para continuarem vivos - e se eles sobreviverão ao mundo que habitam, para encontrá-los será preciso seguir 
adiante e ouvir, ouvir bem, ouvir com atenção, até encontrar a última voz humana viva.

\section{Referências}

ALEKSIÉVITCH, Svetlana. Vozes de Tchernóbil. São Paulo: Companhia das Letras, 2016.

ARENDT, Hannah. A condição humana. Rio de Janeiro: Forense Universitária, 2004.

. Entre o passado e o futuro. São Paulo: Perspectiva, 2007.

ASSMANN, Aleida. Espaços da recordação: formas e transformações da memória cultural. Campinas: Editora da UNICAMP, 2011.

CHAKRABARTY, Dipesh. "O clima da história: quatro teses", in Sopro, n. 91, julho de 2013, pp. 1-22; disponível em http://www.culturaebarbarie.org/sopro/n91.html

- "Climate and Capital: On Cojoined Histories", in Critical Inquiry, vol. 41, n. 1, Autumn 2014, pp. 1-23.

DANOWSKI, Déborah; VIVEIROS DE CASTRO, Eduardo. Há um mundo por vir? Ensaio sobre os medos e os fins. Desterro [Florianópolis]: Cultura e Barbárie, 2014.

KOSELLECK, Reinhart. Futuro Passado. Rio de Janeiro: Contraponto, 2016.

LORENZ, Chris. "Blurred Lines: History, Memory and the Experience of Time", in International Journal for History, Culture and Memory, Amsterdam, vol. 2, n. 1, pp. 43-62.

NANCY, Jean-Luc. After Fukushima: The Equivalence of Catastrophes. New York: Fordham University Press, 2015. 
STENGERS, Isabelle. No tempo das catástrofes - resistir à barbárie que se aproxima. São Paulo: Cosac Naify, 2015.

Recebido em 11/12/2016, aceito para publicação em 13/03/2017 